\title{
Two-phase pressure drop during upward cross flow in triangular tube bundle
}

\author{
Fabio Toshio Kanizawa ${ }^{a}$ and Gherhardt Ribatski \\ Escola de Engenharia de São Carlos, University of São Paulo, Av. Trabalhador São Carlense, 400, CEP 13566-590, \\ São Carlos, São Paulo, Brazil - Mechanical Engineering Department. Phone number: +55 16 3373-9415
}

\begin{abstract}
This paper presents experimental results for pressure drop during air-water upward two-phase flow across horizontal triangular tube bundle. It is estimated that more than half of shell-and-tube heat exchangers in industry operate under two-phase flow conditions in the shell side. However the number of research and publications focused on external flow is considerably reduced when compared to intube flow. This study addresses experimental results for pressure drop during external flow of air and water mixtures across a triangular tube bundle counting with $19 \mathrm{~mm}$ OD tubes and $24 \mathrm{~mm}$ transverse pitch, for superficial velocities up to 0.553 and $10 \mathrm{~m} / \mathrm{s}$ for water and air, respectively. For reduced mass velocities, the gravitational pressure drop parcel is dominant, consequently the adoption of an appropriate methodology for void fraction estimative is essential for accurate estimative of the gravitational pressure drop parcel. The experimental results are compared with predictive methods available in the open literature, and an analysis of this comparison is presented.
\end{abstract}

\section{Introduction}

According to Noghrekar et al. [1] and Green and Hetsroni [2], more than half of shell-and-tube heat exchangers in industry operate under two-phase flow conditions in the shell-side. However the number of research and publications for external flow is considerably lower than the number for intube flow.

Reliable predictive methods for heat transfer coefficient, pressure drop and void fraction are needed for the thermo-hydraulic design of heat exchangers. The heat transfer coefficient is related to the equipment thermal capacity, the pressure drop is related to the required pumping power to propel the flow through the equipment, and the void fraction affects the refrigerant inventory, pressure drop and heat transfer coefficient. In the case of refrigeration industry, the correct estimative of fluid inventory is a key factor for the analysis of economic viability, since the refrigerant cost represents a significant parcel of the system total cost.

Another important aspect concerning external cross flow in tube bundle is the flow induced vibrations (FIV), which as shown by Kanizawa et al. [3], Green and Hetsroni [2] and Pettigrew and Taylor [4, 5] can imply in equipment life cycle reduction due to fretting wear or fatigue, or in worse cases FIVs can cause equipment collapse within few working hours, for conditions of FIV induced by fluid-elastic instabilities.

For vertical upward two-phase flow, the total pressure drop is composed of friccional, gravitational and accelerational parcels. The last one is more pronounced for conditions of phase change along the fluid path and for conditions with significant variations of density and cross sectional area. The gravitational and accelerational parcels are functions of phases densities and void fraction.

This study aims to contribute to the knowledge concerning external two-phase flow across tube bundle. The paper presents experimental pressure drop results obtained during upward flows of air-water mixtures across a triangular tube bundle. Experimental results are compared with predictive methods available in the open literature.

\section{Experimental facility and procedure}

Figure 1 depicts the schematics of the experimental facility designed and built for the performance of twophase flow experiments, and Fig. 2 shows a picture of the experimental bench.

\footnotetext{
${ }^{\mathrm{a}}$ Corresponding author: fabio.kanizawa@usp.br
} 


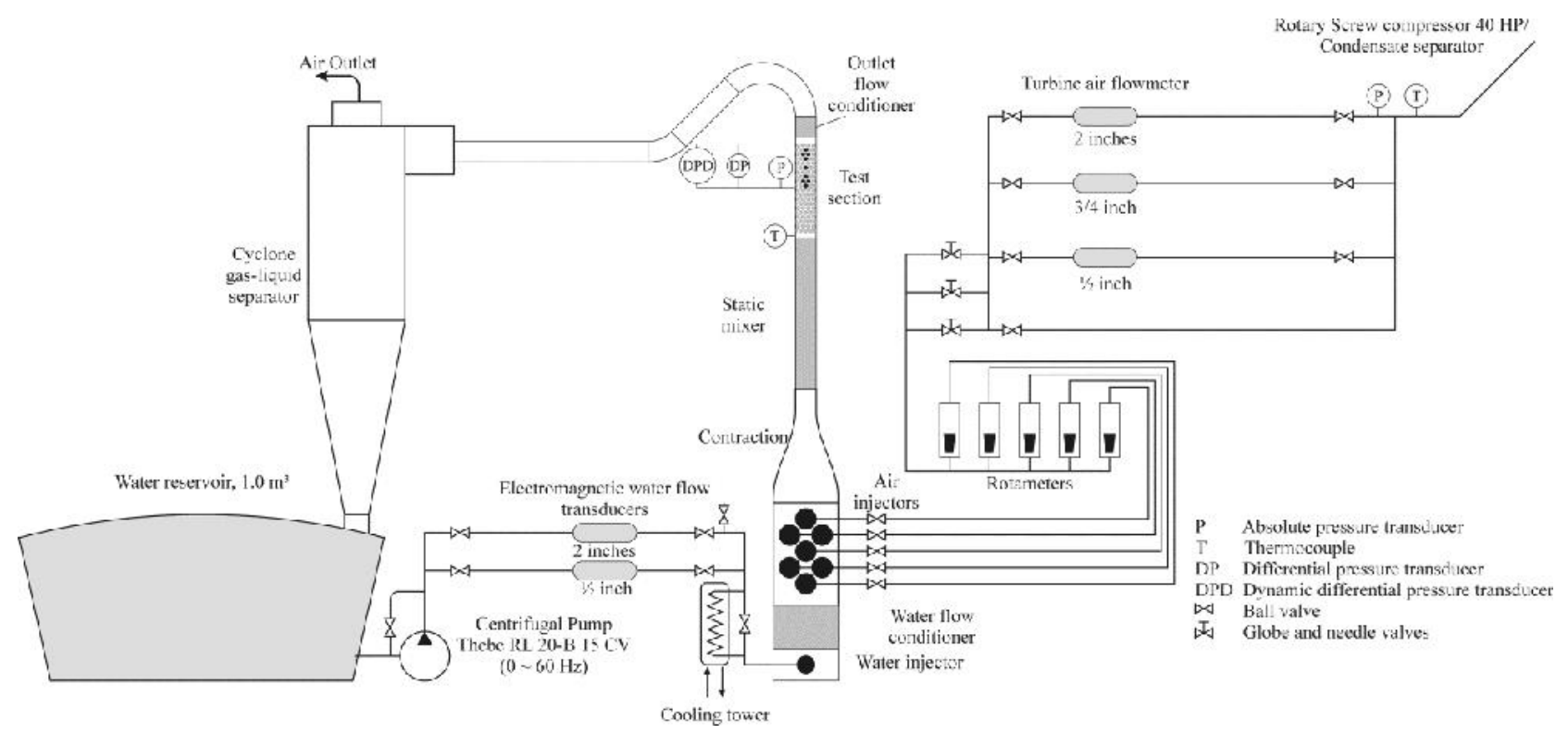

Figure 1. Schematics of experimental facility.

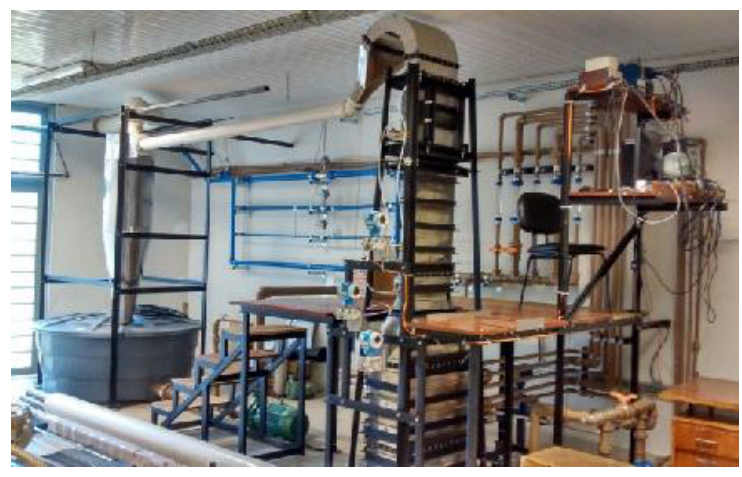

Figure 2. Experimental facility designed and built for the experimental campaign.

The system is composed by water and compressed air loops, measurement system and the test section.

The water loop shown in Fig. 1 consists of a reservoir, an $11.4 \mathrm{~kW}$ centrifugal pump controlled by a variable frequency drive and electromagnetic volumetric flow meters. The electromagnetic flow meters presents uncertainty of $0.5 \%$ of the measured value, and maximum flow rates of 6.4 and $56 \mathrm{~m}^{3} / \mathrm{h}$ for the transducer of $1 / 2$ and 2 inches, respectively $\left(0.00178\right.$ and $\left.0.01560 \mathrm{~m}^{3} / \mathrm{s}\right)$.

Just downstream the flow measurement devices, a heat exchanger was installed to control the water temperature. It consists of a shell and tube heat exchanger, and operates with water cooled by an evaporative cooling tower, not shown in Fig. 1. This heat exchanger is used to avoid significant water temperature changes during the experiments.

The air is compressed by a $40 \mathrm{HP}$ rotary screw compressor, with operating gauge pressure of 7.5 bars and maximum flow rate of $4672 \mathrm{Nl} / \mathrm{min}\left(0.0779 \mathrm{Nm}^{3} / \mathrm{s}\right)$. Just downstream the compressor, an aftercooler was installed to cool down the air and to favor the air moisture condensation in the reservoir, which counts with a liquid trap in the bottom region. The aftercooler operates with water from the evaporative cooling tower. These devices are not shown in Fig. 1.

A pressure regulating valve was installed downstream the reservoir to control the air pressure in the flow measuring section, corresponding to the turbine flowmeters in Fig. 1. With a constant pressure upstream the needles and globe valve, it is possible to perform a manual control of the flow rate, without an automated closed loop control system.

Air flow rate was measured with three turbine flow meters, presenting maximum ranges of $8.5,85$ and 340 $\mathrm{m}^{3} / \mathrm{h}$ for the $1 / 2,1$ and 2 inches transducers, respectively (0.002, 0.023 and $0.094 \mathrm{~m}^{3} / \mathrm{s}$ ), with measurement uncertainty lower than $1 \%$ of the measured value. Close to the transducers, a PT100 and an absolute pressure transducer were installed to determine air thermodynamic state, allowing the determination of air density and therefore the air mass flow rate. In order of covering a broad range of superficial velocities, different flow meter were set according to the experimental condition given by the air and water superficial velocity.

The heat exchangers for the air and water temperature control were used to minimize effects of air contraction and expansion along the test section due to thermal nonequilibrium. Air flow rate was controlled manually through the use of two needle and one globe valve.

Just downstream the controlling valves, five rotameters were installed to check the air flow distribution among the air injectors, to avoid damaging of the injectors due to excessive flow.

The test section set, from bottom to the top region in Fig. 1, consists of water injection and conditioning section, air injection section, contraction, static mixer, the test section and outlet flow conditioner. Downstream the test section outlet, the flow was directed to the gas-liquid cyclone separator, and then water was directed to the reservoir, and air to the outside of the laboratory.

Water was injected with a perforated tube, and conditioned with honeycomb flow straightener. Air was 
injected through seven membrane air injectors distributed in five rows. The with maximum flow rate of each injector is $816 \mathrm{Nl} / \mathrm{min}$. The static mixer was built and installed to distribute the phases uniformly along the cross section, in order of mimicking flow distribution in the core of a large scale industrial shell and tube heat exchanger.

The test section consists of a triangular tube bundle (staggered with $30^{\circ}$ ), counting with $19 \mathrm{~mm}$ OD tubes distributed in 20 rows and 4 columns. In the test section side walls, half tubes were installed to avoid preferable bypass flow, as recommended by Chisholm [6]. The transverse pitch is equal to $24 \mathrm{~mm}$, resulting in a transverse pitch per diameter ratio equal to 1.26 .

Pressure taps were installed after the seventh and eighteenth rows, and the pressure drop was measured with three Endress Hauser PMD75 differential pressure transducers, ranging from -3 to $3 \mathrm{kPa},-3$ to $10 \mathrm{kPa}$ and -3 to $300 \mathrm{kPa}$, and with uncertainty of $0.075 \%$ of the set span.

A National Instruments acquisition system installed in a desktop computer was employed for the signal measurement and for the pump control. The acquisition program was implemented in LabView 8.2.

The text section contains two side windows to allow visual identification of the flow pattern.

\subsection{Experimental procedure}

Previously to the beginning of the experiments, the cooling tower, the water pumps feeding the heat exchangers and the compressor are turned on. Then, the transducers are checked in order to identify possible incoherencies.

After this initial procedure, the electromagnetic flow meter is selected based on its measurement range. Then, the water pump is turned on, and its superficial velocity is adjusted through a closed loop PI (proportional and integral) controller implemented in LabView and actuating through the data acquisition system.

Simultaneously to the adjustment of the liquid flow rate, a turbine flow meter is selected based on the desired air flow rate, and the air superficial velocity is adjusted by manipulating needle and globe valves.

Once the air and water superficial velocities are set, unsteadiness of the system based on pressure drop and flow rate variations are checked. Then, the data log is started and the signals are acquired for at least one minute.

After acquiring the experimental data, the air flow rate is adjusted for a new condition characterized by a different air superficial velocity, and the procedure abovementioned is repeated and data for a new experimental condition is obtained.

Experimental conditions covered water superficial velocities between 0.020 and $0.553 \mathrm{~m} / \mathrm{s}$, and air superficial velocities between 0.20 and $10 \mathrm{~m} / \mathrm{s}$.

\subsection{Data reduction}

This study aims to present experimental results for pressure drop during two-phase upward crossflow in tube bundle. The total pressure drop is composed of the accelerational, gravitational and frictional parcels. The first one can be considered null due to the fact that the flow is adiabatic, the cross sectional area in the pressure taps points are the same and the variation of density is not significant. The gravitational parcel $\Delta p_{\text {grav }}$ is estimated according to the following relationship, derived from continuity and momentum conservation equations:

$$
\Delta p_{\text {grav }}=\left[\rho_{g} \alpha+\rho_{l}(1-\alpha)\right] g \Delta h
$$

where $\alpha$ is the void fraction, $\rho$ is the phase density, $g$ is the gravitational acceleration, $\Delta h$ is the height difference between the pressure taps, and the subscripts $l$ and $g$ refers to the liquid and gas phases, respectively.

The void fraction $\alpha$ is evaluated based on predictive methods available in the literature (Feenstra et al. [10], Schrage et al. [11], Dowlati et al. [12], Xu et al. [13] and the homogenous model).

The total pressure drop is given by the differential pressure transducers. Then, the frictional pressure drop parcel can be evaluated as follows:

$$
\Delta p_{\text {fric }}=\Delta p_{\text {Total }}-\Delta p_{\text {grav }}
$$

The superficial liquid and gas velocities, $j_{l}$ and $j_{g}$ respectively, are evaluated based on the minimum flow cross sectional area, corresponding to the minimum distance between the tubes of the same row. Reynolds number for single-phase flow is based on the tube external diameter and the superficial velocities.

\subsection{Experimental facility validation}

Initially, single-phase experiments were performed and their results were compared against predictive methods from the literature in order of evaluate the pressure drop measurements.

Figures 3 and 4 show the experimental results for water and air single-phase flows, respectively. These figures also display comparisons against the single-phase pressure drop results and the predictive methods of ESDU [7], Gaddis [8] and Zukauskas and Ulinskas [9]. Based on both figures, it can be concluded that the experimental results and the predictions agree reasonably well. Zukauskas and Ulinskas [9] method predicted 95 and $53 \%$ of experimental results for water and air flow within an error band of $\pm 30 \%$, respectively. ESDU [7] predicted 72 and $37 \%$, and Gaddis [8] predicted 35 and $21 \%$ of experimental results for water and air, respectively. 


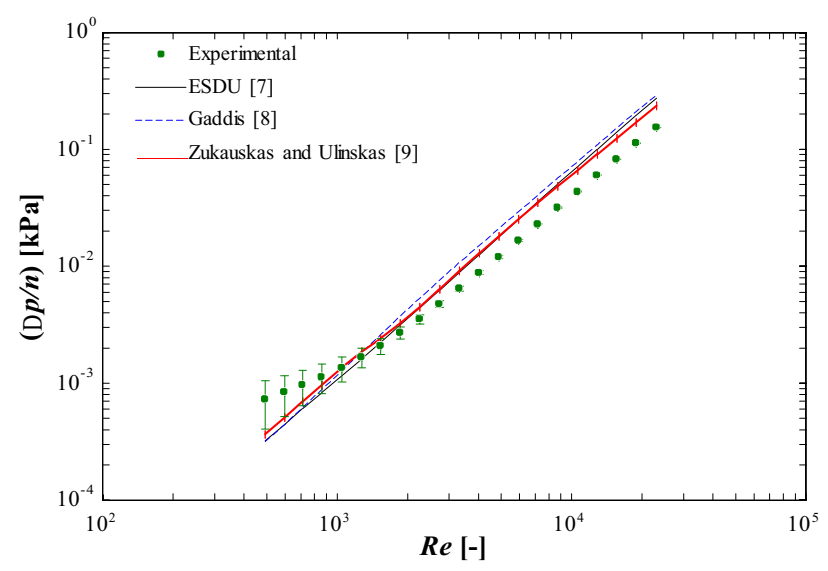

Figure 3. Experimental results for water single-phase flow.

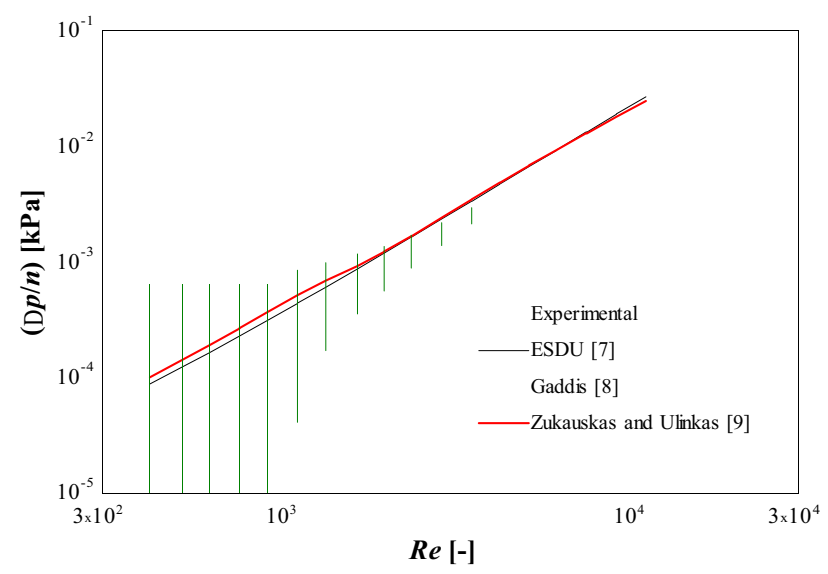

Figure 4. Experimental results for air single-phase flow.

It must be highlighted that the predictive methods for single-phase pressure drop across tube bundles presents deviation higher than $20 \%$ from each other depending on the Reynolds number, indicating that there is no consensus about predictive methods for external flow across tube bundle, even for single-phase condition.

\section{Experimental results and discussion}

For certain liquid superficial velocities, the maximum air flow velocity was not obtained due to the harshness of liquid slug passages to prevent damage of the test section. The experimental conditions for the air superficial velocity were distributed according to a geometric progression, between its minimum and maximum values.

Figure 5 presents experimental results for total pressure drop $\Delta p_{\text {Total }}$ across eleven tube rows. According to Fig. 5, for reduced liquid superficial velocities $j_{l}$, the total pressure drop decreases with increasing the gas velocity $j_{g}$. On the other hand, under conditions of high liquid velocities, the pressure drop increases with increasing gas velocity.

The reduction of total pressure drop with increasing the superficial gas velocity for reduced liquid velocities is related to the increment of the void fraction with increasing gas velocity. This implies a reduction of the gravitational pressure drop parcel and consequently of the total pressure drop. For conditions of low liquid velocities, the gravitational pressure drop parcel corresponds to a significant parcel of the total pressure drop, and even with the increment of the frictional parcel due to the increment of flow velocity, the total pressure drop decreases. Therefore the adoption of an appropriate predictive method for void fraction estimative is essential for the accurate estimative of the frictional pressure drop parcel.

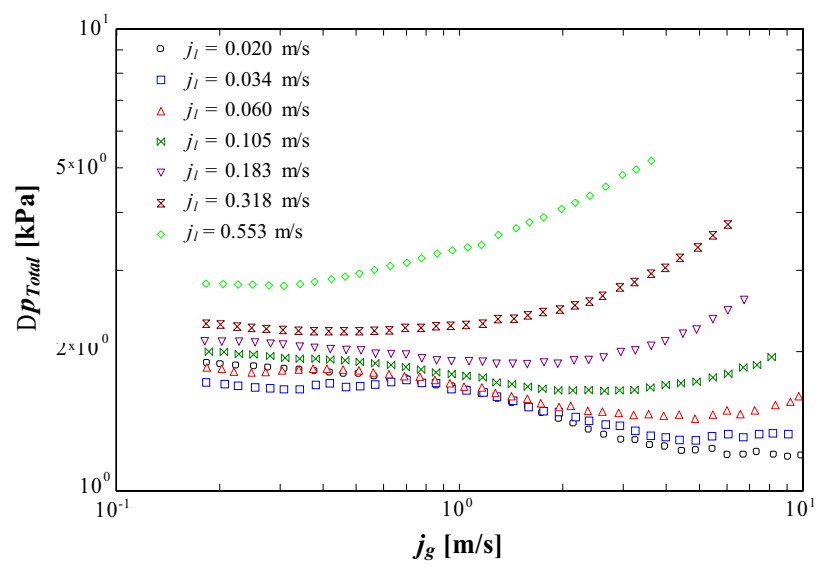

Figure 5. Experimental result for pressure drop during twophase flow, between eleven tube rows.

Table 1. Comparison of experimental results and the predictive methods for frictional pressure drop, assuming a set of void fraction predictive methods for gravitational pressure drop estimative.

\begin{tabular}{|c|c|c|c|c|c|c|c|c|c|c|c|c|c|c|}
\hline \multirow{2}{*}{$\begin{array}{l}\text { Predictive } \\
\text { method } \\
\text { for } \alpha\end{array}$} & \multicolumn{2}{|c|}{ Diehl [14] } & \multicolumn{2}{|c|}{$\begin{array}{c}\text { Dowlati et al. } \\
{[15]}\end{array}$} & \multicolumn{2}{|c|}{$\begin{array}{c}\text { Grant and } \\
\text { Chisholm [16] }\end{array}$} & \multicolumn{2}{|c|}{$\begin{array}{c}\text { Ishihara et al. } \\
\text { [17] }\end{array}$} & \multicolumn{2}{|c|}{$\begin{array}{c}\text { Schrage et al. } \\
{[11]}\end{array}$} & \multicolumn{2}{|c|}{ Xu et al. [13] } & \multicolumn{2}{|c|}{$\begin{array}{c}\text { Homogeneous } \\
\text { model }\end{array}$} \\
\hline & $\varepsilon$ & $\gamma_{30}$ & $\varepsilon$ & $\gamma_{30}$ & $\varepsilon$ & $\gamma_{30}$ & $\varepsilon$ & $\gamma_{30}$ & $\varepsilon$ & $\gamma_{30}$ & $\varepsilon$ & $\gamma_{30}$ & $\varepsilon$ & $\gamma_{30}$ \\
\hline $\begin{array}{l}\text { Feenstra } \\
\text { et al. }[10]\end{array}$ & 66 & 18 & 81 & 4 & 57 & 17 & 430 & 4 & 83 & 4 & 86 & 4 & 62 & 11 \\
\hline $\begin{array}{l}\text { Schrage } \\
\text { et al. }[11]\end{array}$ & 106 & 32 & 130 & 11 & 140 & 50 & 2103 & 9 & 134 & 11 & 120 & 9 & 93 & 54 \\
\hline $\begin{array}{c}\text { Dowlati } \\
\text { et al. }[12]\end{array}$ & 68 & 16 & 83 & 3 & 62 & 10 & 361 & 3 & 85 & 3 & 87 & 3 & 66 & 8 \\
\hline $\begin{array}{c}\text { Xu et al. } \\
\text { [13] }\end{array}$ & 65 & 23 & 82 & 5 & 61 & 21 & 1909 & 5 & 84 & 5 & 85 & 4 & 64 & 11 \\
\hline $\begin{array}{l}\text { Hom. } \\
\text { model }\end{array}$ & 74 & 14 & 88 & 0 & 72 & 0 & 193 & 9 & 89 & 1 & 90 & 1 & 74 & 4 \\
\hline
\end{tabular}


The augmentation of the total pressure drop with increasing superficial gas velocity is due to the fact that under conditions of high liquid superficial velocities, the gravitational parcel corresponds to a reduced parcel of the total pressure drop. So, its reduction with increasing superficial gas velocity is overcome by the increment of the frictional parcel with increasing the two-phase flow velocity.

Table 1 presents the statistical analysis of the comparison between the experimental results for frictional pressure drop and estimative based on predictive methods available in the open literature. In this table the experimental data are compared against the predictive methods proposed by Diehl [14], Dowlati et al. [15], Grant and Chisholm [16], Ishihara et al. [17], Schrage et al. [11], Xu et al. [13] and the homogeneous model, described by Collier and Thome [18] for horizontal flow. The methods proposed by Feenstra et al. [10], Schrage et al. [11], Dowlati et al. [12], Xu et al. [13] and the homogenous model were considered for void fraction estimative, and therefore for the gravitational pressure drop parcel evaluation. In this table, the absolute percentage of data predicted within $\pm 30 \%$ of error band $\gamma_{30}$ and the mean absolute error $\varepsilon$ are presented. The mean absolute error was calculated as follows:

$$
\varepsilon=\sum_{i=1}^{N}\left|\frac{\Delta p_{\text {fric, Estimated }, i}-\Delta p_{\text {fric, Experimental }, i}}{\Delta p_{\text {fric }, \text { Experimental }, i} N}\right|
$$

For each void fraction method the gravitational parcel of the pressure drop was evaluated, and the frictional parcel was obtained from Eq. (2). The predictive methodologies for frictional pressure drop are based on two-phase multiplier, but some of them do not specify which method should be used for the evaluation of single-phase flow pressure drop. For these cases, the method proposed by Zukauskas and Ulinskas [9] was adopted for the estimative of single-phase pressure drop, since it gives the best prediction of the single-phase pressure drop experimental results obtained in the present study, as shown in the item 2.3 .

According to Tab. 1, the frictional pressure drop evaluated according to the homogenous model assuming the gravitational pressure drop evaluated according to Schrage et al. [11] presents the highest percentage of data within an error band of $\pm 30 \%$, with $54 \%$ of predictions within this error band.

Similarly, the method of Grant and Chisholm [16] assuming gravitational pressure drop given by Schrage et al. [11] method gives better predictions than the others combinations, with $50 \%$ of data within $\pm 30 \%$, however it gives high mean absolute error.

The fact that all predictive methods present high mean absolute error is due to the high uncertainties of the measurements under conditions of low pressure drops. Additionally, deviations of tens of $\mathrm{Pa}$ (millimeters of water column) between the predictive and the estimated values correspond to a high percentage of the frictional pressure drop for these conditions, which contribute to the high mean deviation.
Figure 6 depicts the estimated frictional pressure drop per row, considering the gravitational pressure drop evaluated assuming the void fraction given by the method of Schrage et al. [11]. According to this method, the void fraction $\alpha$ increases with increasing mass velocity and vapor quality, and therefore the gravitational pressure drop parcel decreases with mass velocity and vapor quality.

Figure 7 illustrates the variation of $\Delta p_{\text {grav }}$ with the gas superficial velocity for different liquid superficial velocities with the void fraction calculated according to the method of Schrage et al. [11]. This figure shows that $\Delta p_{\text {grav }}$ increases with mass velocity, on contrary to the expectation of decrement with mass velocity. This behavior is due to the fact that for a given $j_{g}$ the vapor quality decreases with the increment of $j_{l}$, and for this method and operational ranges the vapor quality influence overcomes the mass velocity influence.

Under conditions of reduced liquid and gas superficial velocities, the gravitational pressure drop parcel assuming void fraction given by $\mathrm{Xu}$ et al. [13], Schrage et al. [11] and Dowlati et al. [12] methods is even higher than the total pressure drop, indicating that these methods are not valid for these operational conditions. In fact, for reduced liquid velocities the gravitational parcel is dominant, and the correct choice of an appropriate void fraction predictive method is essential for the determination of the gravitational, and consequently the frictional parcel of the pressure drop.

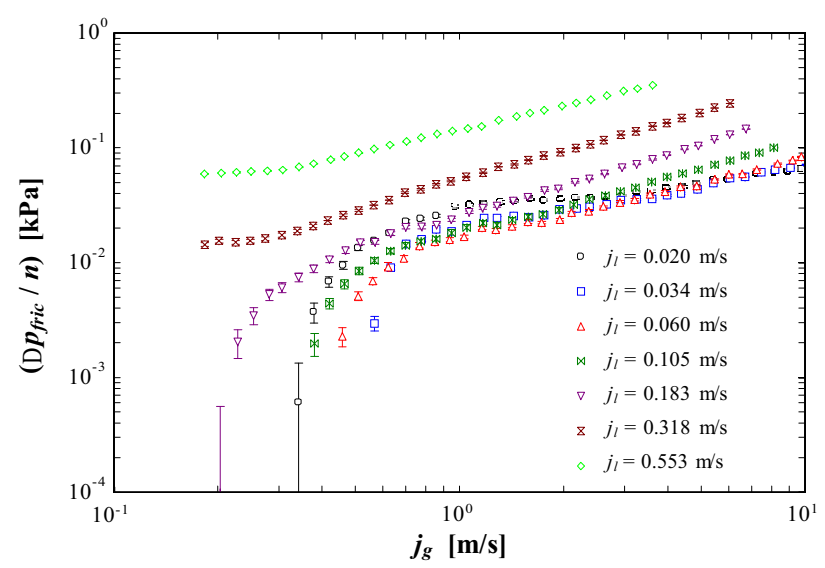

Figure 6. Frictional pressure drop parcel assuming the predictive method of Schrage et al. [11] for void fraction.

Figures 8 and 9 compares the trends of the experimental results and predictive methods for frictional pressure drop parcel during two-phase flow for liquid superficial velocities of 0.020 and $0.318 \mathrm{~m} / \mathrm{s}$, respectively. As can be observed from Fig. 8, none of the methodologies is capable of predicting the experimental trend of the pressure drop with varying the superficial gas velocity for the lower liquid superficial velocity. In fact, most of the methods under predict the experimental data, except by Ishihara et al. [17] methodology that over predict the experimental results.

For $j_{l}$ of $0.318 \mathrm{~m} / \mathrm{s}$, the methods proposed by Diehl [14], Grant and Chisholm [16] and the homogenous model presented good agreement with the experimental 
trends according to Fig. 9. Moreover, it is surprising that Diehl [14] provides good predictions of the experimental results, since this method was developed based on experimental data for vertical downward flow.

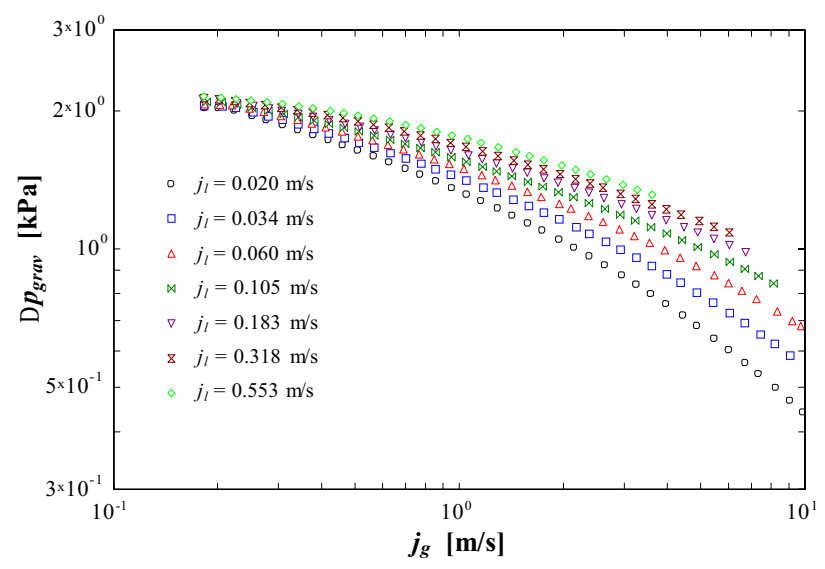

Figure 7. Gravitational pressure drop parcel between eleven tube rows estimated considering Schrage et al. [11] method for void fraction estimative.

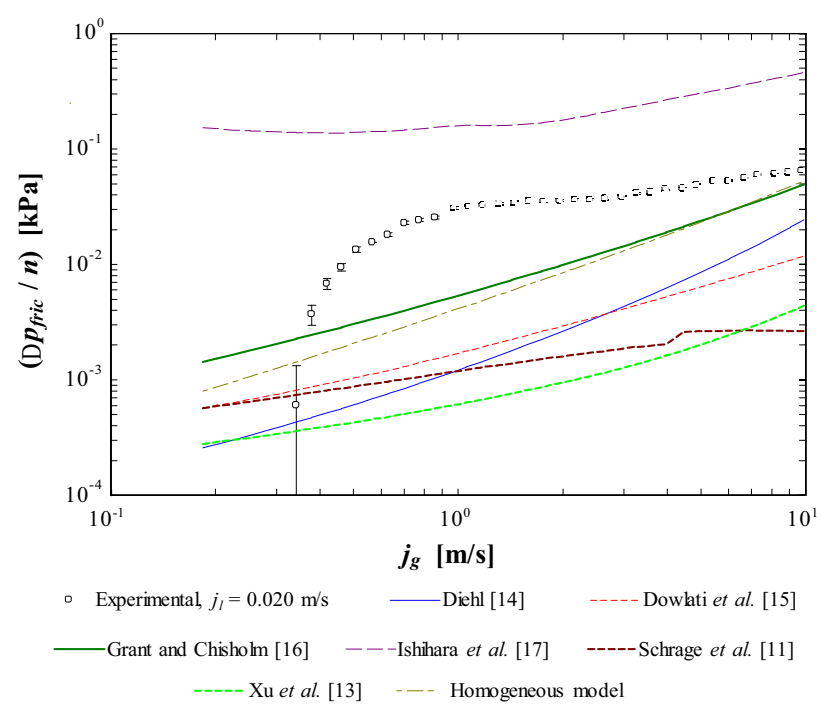

Figure 8. Comparison of experimental results and predictive methods for frictional pressure drop, $j_{l}=0.020 \mathrm{~m} / \mathrm{s}$.

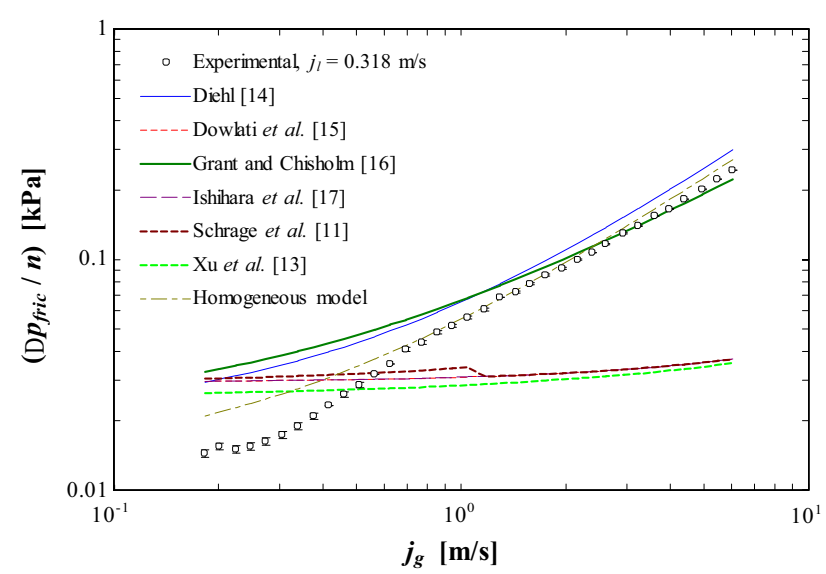

Figure 9. Comparison of experimental results and predictive methods for frictional pressure drop, $j_{l}=0.318 \mathrm{~m} / \mathrm{s}$.
According to the methods proposed by Dowlati et al. [15], Schrage et al. [11], Ishihara et al. [17] and $\mathrm{Xu}$ et al. [13] the pressure drop varies with the gas superficial velocity within a narrow range. It must be mentioned that these methods were developed based on the methodology proposed by Chisholm [19] for intube two-phase flow, which in turn takes the Martinelli parameter as the main variable for the determination of two-phase multiplier.

The Martinelli parameter, firstly presented by Lockhart and Matinelli [20], is given as the square root of the ratio of the pressure drop for the mixture flowing as liquid and gas inside round tubes, with the friction factor estimated according to Blasius [21] correlation for turbulent flow regime. For the case of external flow in tube bundle, the friction factor cannot be represented by a single Blasius form, even for turbulent condition, as discussed by Ulbrich and Mewes [22], and consequently the adoption of the Matinelli parameter to describe the trends of pressure drop during external flow can be not representative of the physical mechanisms involved.

\section{Concluding remarks}

This study presents pressure drop experimental results obtained during single and two-phase upward crossflow of air-water mixtures in triangular tube bundle. The following specific conclusions can be drawn from an analysis of this database:

- Frictional pressure drop increases with increasing mass flux during single-phase flow. The methodology proposed by Zukauskas and Ulinskas [9] presented the best prediction of experimental results, predicting 95 and $53 \%$ of experimental results within an error band of $\pm 30 \%$ for air and water, respectively. It should be highlighted that predictive methods for single-phase flow pressure drop present deviation higher than $20 \%$ among them, indicating that there is no generalized methodology even for single-phase flow.

- Experimental results for pressure drop during twophase flow were presented. For reduced liquid superficial velocities, the total pressure drop decreases with increasing the superficial gas velocity, due to the reduction of the gravitational pressure drop parcel. For intermediary and high liquid superficial velocity, the total pressure drop increases with increasing the superficial gas velocity, and under these conditions the gravitational parcel corresponds to a lower parcel of the total pressure drop.

- Predictive methods for void fraction and frictional pressure drop parcel were evaluated. Best predictions of the total pressure drop were provided by the combinations of homogeneous model and Grant and Chisholm [16] predictive methods for frictional pressure drop with the void fraction predictive method proposed by Schrage et al. [11]. Nonetheless, none of the predictive method evaluated was able to predict the experimental database accurately, indicating that there is no generalized methodology 
for pressure drop estimative during two-phase flow across tube bundles.

\section{Acknowledgements}

The authors gratefully acknowledge a doctorate scholarship to the first author by Fapesp (São Paulo Research Foundation) under Contract Number 2010/20670-2, and the financial support to this study under Contract Number 481044/2010-8 given by CNPq (The National Council for Scientific and Technological Development, Brazil). The technical support by $\mathrm{Mr}$. Helio J. D. Trebi and Antonio A. P. Silva is also deeply recognized.

\section{References}

1. G. R., Noghrehkar, M. Kawaji, and A. M. C. Chan. Int. J. Multiphas. Flow, 25(5), 857-874 (1999).

2. S. J. Green, Hetsroni, G. Int. J. Multiphas. Flow, 21 1-97 (1995).

3. F. T. Kanizawa, L. R. P. de Oliveira, G. Ribatski ASME 2012 Fluids Engineering Division Summer Meeting, 79-88 (2012).

4. M. J. Pettigrew, C. E. Taylor. J. Fluids Struct., 18(5) 469-483 (2003).

5. M. J. Pettigrew, C. E. Taylor. J. Fluids Struct., 18(5) 485-500 (2003).

6. D. Chisholm. Int. J. Heat Fluid Fl., 5(1) 51-53 (1984).

7. ESDU International. ESDU 79034 - Crossflow pressure loss over banks of plain tubes in square and triangular arrays including effects of flow direction. (2007).

8. E. S. Gaddis. L1.4 Pressure Drop of Tube Bundles in Cross Flow. In: Verein Deutscher Ingenieure. VDI Heat Atlas Second Edition. 1076-1091 (2010).

9. A. Zukauskas, R. Ulinskas. 2.2.4 Banks of plain and finned tubes. In: Heat Exchanger Design Handbook 2 - Fluid mechanics and heat transfer. (1983).

10. P. A. Feenstra, D. S. Weaver, R. L. Judd. Int. J. Multiphas. Flow, 26(11) 1851-1873 (2000).

11. D. S. Schrage, J. T. Hsu, M. K. Jensen. AIChE J., 34(1) 107-115 (1988).

12. R. Dowlati, M. Kawaji, D. Chisholm, A. Chan. AIChE J., 38(4), 619-622 (1992).

13. G. P. Xu, C. P. Tso, K. W. Tou. Int. J. Multiphas. Flow, 24(8) 1317-1342 (1998).

14. J. E. Diehl. Petroleum Refiner., 36(10) 147-153 (1957).

15. R. Dowlati, M. Kawaji, A. Chan. AIChE J., 36(5) 765-772 (1990).

16. I. D. R. Grant, D. J. Chisholm. Heat Trans. T. ASME, 101(1) 38-42 (1979).

17. K. Ishihara, J. W. Palen, J. Taborek. Heat Transfer Eng., 1(3) 23-32 (1980).

18. J. G. Collier, J. R. Thome. Convective boiling and condensation. (1994).

19. D. Chisholm. Int. J. Heat Mass Tran., 10(12) 17671778 (1967).
20. R. W. Lockhart, R. C. Martinelli. Chem. Eng. Prog., 45(1) 39-48 (1949).

21. H. Blasius. Sonderabdruck aus der Zeitschrift des Vereines deutscher Ingenieure, Jahrgang 1912, S. 639 1-5 (1912).

22. R. Ulbrich, D. Mewes, D. Int. J. Multiphas. Flow, 20(2) 249-272 (1994) 